\title{
Vibrational Communication of Scolypopa australis (Walker, 1851) (Hemiptera: Ricaniidae)—Towards a Novel Sustainable Pest Management Tool
}

\author{
Nicola Jayne Sullivan ${ }^{1, *} \mathbb{\infty}$, Sabina Avosani ${ }^{2,3,4} \oplus$, Ruth C. Butler ${ }^{1}\left(\mathbb{D}\right.$ and Lloyd D. Stringer ${ }^{1}(\mathbb{D}$ \\ 1 The New Zealand Institute for Plant and Food Research Limited, Private Bag 4704, Christchurch Mail Centre, \\ Christchurch 8140, New Zealand; ruth.butler@plantandfood.co.nz (R.C.B.); \\ lloyd.stringer@plantandfood.co.nz (L.D.S.) \\ 2 DICAM Department of Civil, Environmental and Mechanical Engineering, University of Trento, \\ 38123 Trento, Italy; sabina.avo@gmail.com \\ 3 Research and Innovation Center, Fondazione Edmund Mach, 38010 San Michele all'Adige, Italy \\ 4 CIHEAM-Bari, 70010 Valenzano, Italy \\ * Correspondence: nicola.sullivan@plantandfood.co.nz
}

Citation: Sullivan, N.J.; Avosani, S.; Butler, R.C.; Stringer, L.D. Vibrational Communication of Scolypopa australis (Walker, 1851) (Hemiptera:

Ricaniidae)—Towards a Novel Sustainable Pest Management Tool. Sustainability 2022, 14, 185. https:// doi.org/10.3390/su14010185

Academic Editor: Imre J. Holb

Received: 4 November 2021

Accepted: 21 December 2021

Published: 24 December 2021

Publisher's Note: MDPI stays neutral with regard to jurisdictional claims in published maps and institutional affiliations.

Copyright: (C) 2021 by the authors. Licensee MDPI, Basel, Switzerland. This article is an open access article distributed under the terms and conditions of the Creative Commons Attribution (CC BY) license (https:// creativecommons.org/licenses/by/ $4.0 /)$.

\begin{abstract}
A study was undertaken to determine whether Scolypopa australis, the passionvine hopper, communicates using substrate-borne vibrations, as its use of such signals for communication is currently unknown. This insect is a costly pest to the kiwifruit industry in New Zealand, where few pest management tools can be used during the growing season. Vibrations emitted by virgin females and males of $S$. australis released alone on leaves of Griselinia littoralis were recorded with a laser vibrometer to identify and characterise potential spontaneous calling signals produced by either sex. In addition to single-insect trials, preliminary tests were conducted with female-male pair trials to determine whether individuals exchanged signals. The signal repertoire of $S$. australis includes a male calling signal and two female calling signals. However, no evidence of duetting behaviour that is potentially necessary for pair formation has been found to date. Our outcome suggests that a deeper understanding of the role of vibrational communication employed by S. australis is needed, and by disclosing the pair formation process, a new residue-free pest management tool against this pest may be developed. In addition, this vibration-based tool could contribute to future biosecurity preparedness and response initiatives.
\end{abstract}

Keywords: biotremology; vibration; communication; residue-free; kiwifruit; Actinidia; passionvine hopper; behavioural manipulation

\section{Introduction}

The passionvine hopper, Scolypopa australis (Walker, 1851) (Hemiptera: Ricaniidae), is a polyphagous phloem-feeding insect and is a pest of kiwifruit belonging to the cultivars Actinidia chinensis (Planch) var. deliciosa and A. chinensis var. chinensis grown in New Zealand. As it feeds, it exudes honeydew, which promotes the growth of sooty moulds. Sooty mould-covered kiwifruit cannot be easily cleaned or be exported to international markets, costing the New Zealand kiwifruit industry NZD 77 million per annum [1]. Due to the characteristics of the fruit themselves (particularly the hairiness of the skin) and because kiwifruit grow under the canopy protected from weathering elements like ultra-violet light exposure and rainfall, insecticidal sprays do not adequately degrade before harvesting and cannot be used for much of the season $[2,3]$. As such, there are few tools available to manage this pest in the crop during the growing season. For all these reasons, novel and eco-friendly control strategies are urgently needed.

Biotremology is an emerging field of science providing innovative approaches to manipulating insect behaviours by transmitting substrate-borne vibrations along plants [4]. Species-specific vibrational signals have been applied in the field against piercing-sucking 
pests like the brown marmorated stink bug, Halyomorpha halys (Stål 1855) (Hemiptera: Pentatomidae) [5,6], and the grapevine leafhopper, Scaphoideus titanus (Ball 1832) (Hemiptera: Cicadellidae) $[7,8]$. Biotremology offers an eco-friendly tool (i.e., no residues are created by the vibrations and due to its spray-free nature, its application is not reliant on fossil fuelderived carbon) that could support other integrated pest management strategies, therefore reducing the application of insecticides. In addition to its potential for pest management, biotremology could also be used in biosecurity systems, for example, to attract and kill insects like hemipterans, for which there are few effective surveillance tools available to traps.

Vibrations have been transmitted along the structures on which plants grow by sophisticated devices like electrodynamic exciters or mini shakers [9,10], although cheaper options like piezoelectric accelerometers may potentially be used as well [11]. Given that substrate-borne vibrations are optimally transmitted when the plants are supported by wires (i.e., as in vineyards [10]), a vibration-based pest control tool would be compatible with several orchard-growing architectures, including those of kiwifruit that have horizontal structural wires to support the growing plants. Very little is known about how $S$. australis communicates with con-specific individuals. If $S$. australis communicates using substrate-borne vibrations, key behaviours such as mating and feeding could be hampered by the transmission of species-specific stimuli. For example, biotremology could provide a mechanism to reduce the sooty mould prevalence from the production of honeydew by interfering with the feeding of $S$. australis or by reducing their overall persistence in orchards. Furthermore, if $S$. australis behaviour can be successfully manipulated by means of vibrations, this pest management strategy would support the industry's transition to carbon-neutral and residue-free food production [12], therefore meeting or exceeding targets identified by initiatives like the European Green Deal [13].

In this light, the aim of the present study was to assess whether $S$. australis uses substrate-borne vibrations to communicate, as the first step towards developing a future vibrational control technique against this pest.

\section{Materials and Methods}

\subsection{Insects}

S. australis nymphs $(\mathrm{n} \approx 1000)$ were field-collected in Te Puke, New Zealand (-37.784, 176.328) from a variety of plant species (Melicytus ramiflorus (Forst and Forst), Ficus macrophylla (Desf. Ex Pers.), Pteridium esculentum (G. Forst)) and were couriered to Plant \& Food Research, Lincoln $(-43.640,172.474)$, New Zealand. Nymphs (approximately 50 per cage) were reared in mesh cages $(45 \times 45 \mathrm{~cm}$, BugDorm, MegaView Science Co., Taiwan $)$ inside a temperature-controlled laboratory $\left(25 \pm 2{ }^{\circ} \mathrm{C}\right)$ on fresh cuttings of Griselinia littoralis (Raoul), which were placed in vials filled with water and replaced once per week. Parafilm ${ }^{\circledR} \mathrm{M}$ tape was placed over the top of the vials and around the base of the plant stem to prevent insects from drowning. Light and humidity were not able to be controlled, so the conditions were ambient humidity and summer sunlight (approx. 13L: 11D). As soon as adults emerged from the last nymphal moult, they were removed from the nymph-rearing cage and sexed. Males and females were separated by gender and age (i.e., adults that emerged in the range of 2-3 days were released in the same cage) to obtain virgin individuals of similar age to be used in the trials. These virgin individuals were maintained as above in numbers varying from 1 to 37, depending on how many had emerged.

\subsection{Experiments}

To record the vibrations emitted by S. australis, we used a laser vibrometer (PDV 100, Polytec, Waldbronn, Germany) focused on a piece of reflective tape $(1 \times 2 \mathrm{~cm})$ superglued to the vein on the abaxial leaf side of the host plant on which the insects were released. The latter consisted of a two-leaf G. littoralis cutting placed in a Parafilm-covered vial filled with water (Figure 1). The recorded signals were digitised at a sample rate of $48,000 \mathrm{kHz}$ and 24-bit resolution using Raven Lite (The Cornell Lab of Ornithology, Ithaca, NY, USA) 
and then analysed using Raven Pro 1.6.1 ${ }^{\circledR}$. All recordings were performed between 09:00 and 16:00 local time. A calling signal was defined as a signal spontaneously emitted by an isolated insect $[14,15]$ and containing a series of pulse trains.

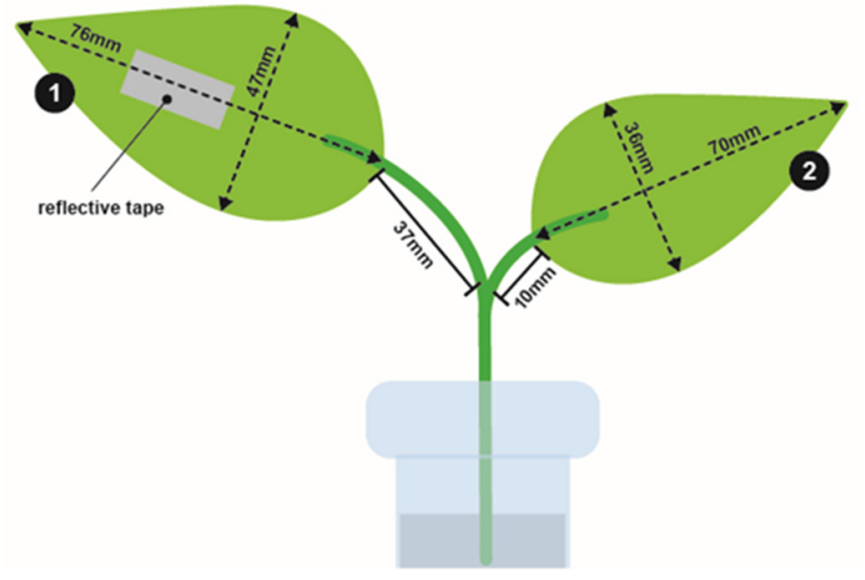

Figure 1. Experimental setup for recording vibrational signals emitted from Scolypopa australis. Recordings were made from leaf 1 , and $S$. australis specimens were placed on leaf 1 in single-insect experiments. In male-female pair experiments, females $S$. australis were placed on leaf 1 and males on leaf 2. Leaf measurements indicate the approximate size and shape of the Griselinia littoralis leaves.

Between February and April 2020 and 2021, we analysed the vibrational behaviour of both single males $(n=54$, in 2020) and single females $(n=33$, in 2021) of $S$. australis. Given that $S$. australis males emit vibration sooner than females after their final moult (authors' personal observations), males were tested from 5 to 10 days after their emergence as adults, whereas females were tested from 11 to 28 days post-emergence. A similar delay in the female vibrational calling activity is common among auchenorrhynchans such as leafhoppers, spittlebugs, and planthoppers [16-18]. The calling behaviour of single males and females was recorded for $30 \mathrm{~min}$, although the recording was prolonged if the insect emitted a calling signal at the end of the recording. New individuals were used each trial. Individual insects were introduced on approximately the middle leaf 1 from a vial by tapping the end of the vial.

Recordings were conducted in a laboratory at Plant \& Food Research, Lincoln, New Zealand in February-March 2020 under ambient temperature and humidity. A desktop lamp was used to provide bright light to the apparatus. From February-April 2021, recordings were conducted in a recently modified sound-dampened room at Plant \& Food Research, Lincoln, New Zealand, again under ambient temperature and humidity. LED room lighting provided bright light on the apparatus. Leaves were not cleaned between individuals. In addition to single individual trials, we recorded the behaviour of male-female pairs $(n=12)$ to investigate whether there was an exchange of vibrational signals between males and females. In the male-female pair experiments, females were introduced on the middle of leaf 1 and then males were introduced on approximately the middle of leaf 2 (Figure 1).

\subsection{Data Analysis}

When a male or female calling signal was recorded, we analysed the time of day when the signal occurred, the time from the insect's release to the first emission of a signal (namely, the calling latency), and the signal characteristics. We measured the length of the calling signal, the number of pulse trains within the calling signal, and the dominant frequency and amplitude of the pulse trains. The duration of the pulses and their dominant frequency were measured by analysing five pulses at the beginning and five pulses at the end of each calling signal. Because there was no true replication (male and female recordings were done at very different times), valid formal statistical comparisons could 
not be made. Therefore, data were examined using exploratory summaries (summary statistics, figures) only.

\section{Results}

In the single male and female trials, 14 males (thus, $25.9 \%$ of the 54 recorded) and 12 of the 33 recorded females (36.3\%) produced at least one calling signal within $30 \mathrm{~min}$. Thirteen male and 11 female calling signals were analysed, and low-quality recordings were discarded. The male calling signal (MC) comprised pulses arranged in pulse trains, whose amplitude increased as the signal progressed (Figure 2A). In contrast, the signal repertoire of the $S$. australis females comprised two calling signals. The female calling signal 1 (FC1) was emitted by 11 females (Figure 2B,C), whereas the female calling signal 2 (FC2) was recorded from only two females (Figure 2D,E). The two female signals differed in the arrangement of the pulse trains, which were more dispersed in FC2 than in FC1 (Figure 2B-E). Exploratory analyses were performed solely on FC1 because of the low number of FC2 calling signals recorded.
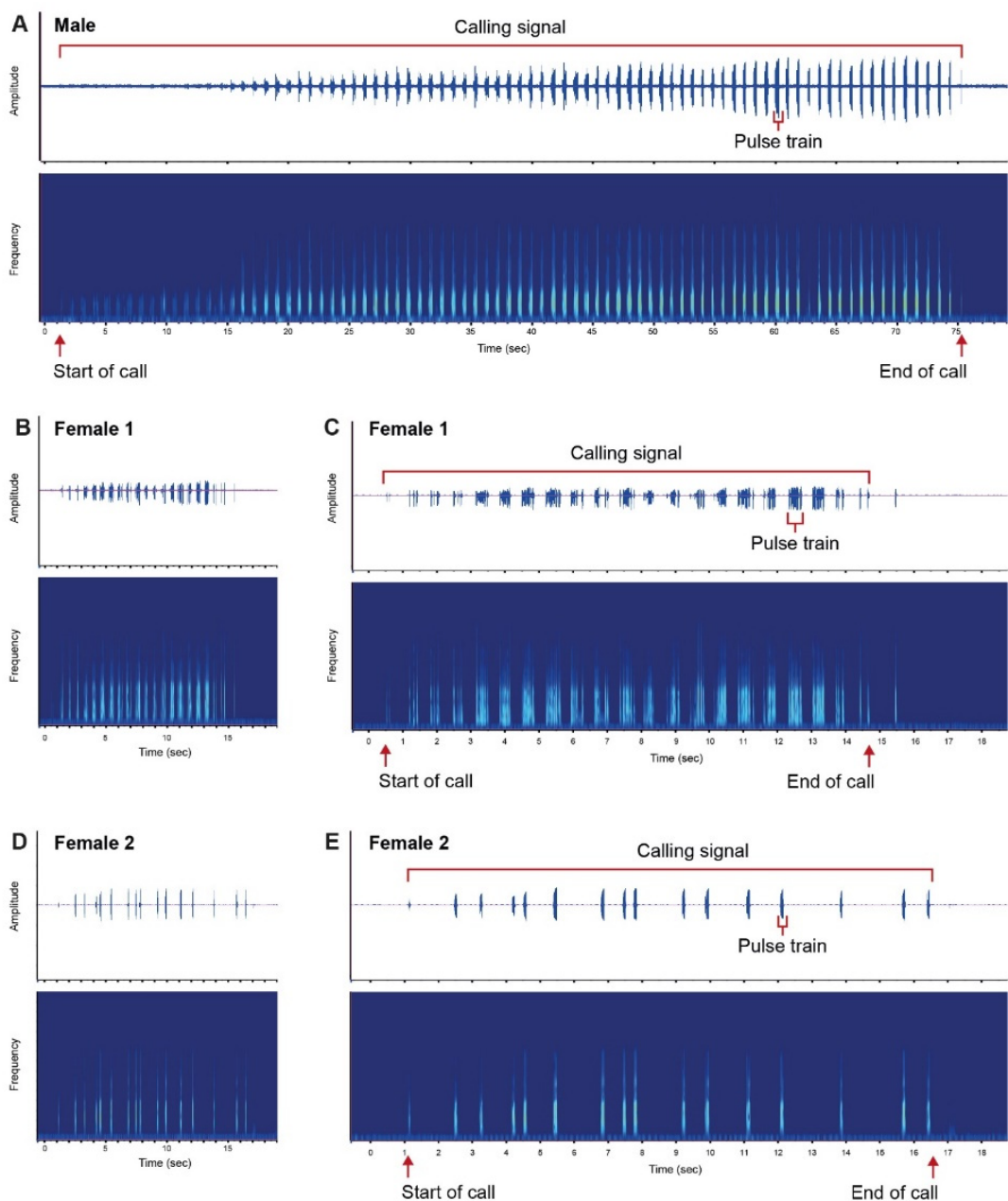

Figure 2. Oscillograms (top) and spectrograms (bottom) of the identified calling signals of Scolypopa australis (A) male calling signal (MC), (B) female calling signal 1 (FC1) at the same time scale as MC and FC2, (C) female calling signal 1 (FC1) on an increased time scale, (D) female calling signal 2 (FC2) at the same time scale as MC and FC1, (E) female calling signal 2 (FC2) on an increased time scale.

Four pairs out of 12 exchanged vibrational signals in the pair trial, but none of the recorded duets led to mating. No mating was observed at any point during the trials. Common behaviours observed included wing-swinging (the individual swayed from side 
to side) and walking around the edge of the leaf. Both males and females displayed these behaviours; however, males appeared to move around the leaf more than females.

Similar to the MC, the FC1 comprised a series of pulses arranged in pulse trains. However, the call latency and call length were longer, and a greater number of pulse trains were emitted within the MC than within the FC1 (Figure 3). The male calling latency was more than twice as great as that of females, and the call length and number of pulse trains were, respectively, 5 and 4.9 times greater in males than in females. Males exhibited greater variation around the three parameters recorded than females (Figure 3 ). We observed that $\approx 30 \%$ of males and $\approx 60 \%$ of females emitted short ( $~ 0.14$ s) pre-calling signal pulses before the calling signal. All tested females emitted post-calling signal pulses, whereas only $\approx 25 \%$ of the males emitted similar pulses after the MC.
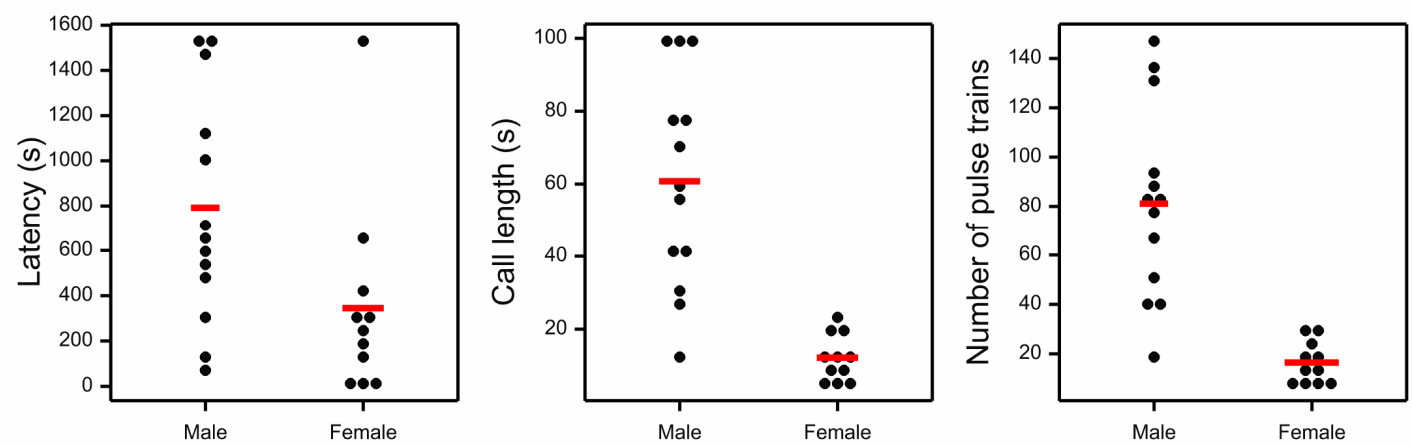

Figure 3. Dot-histograms for the calling latency (s), call length (s), and number of pulse trains per calling signal for each sex of Scolypopa australis. Red bars represent the means.

On average, the dominant frequency of the pulses tended to be higher for males than for females. In both male and female calling signals, the mean dominant frequency was higher for the pulses at the end of the calling signal than for the pulses at the beginning of the signal. However, there was substantial variation around the means (Figure 4). Finally, males and females tended to emit vibrational signals later in the day (Figure 5).
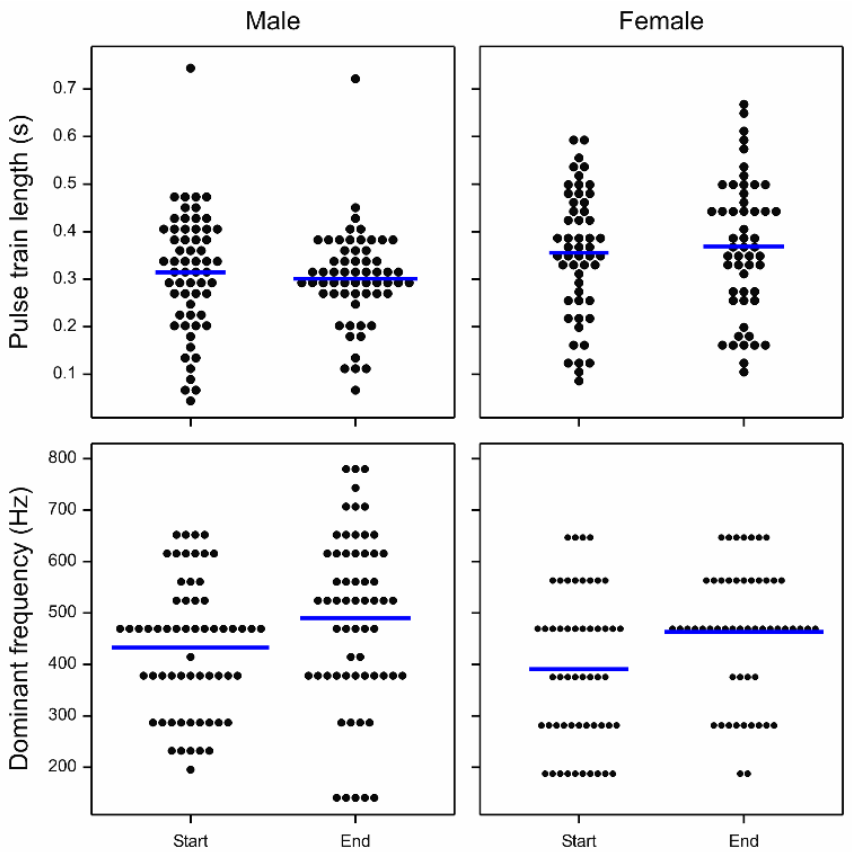

Figure 4. Dot-histograms of pulse train lengths (s) and dominant frequencies (Hz) of the pulses at the start and end of male and female calling signals of Scolypopa australis. Blue bars indicate the means. 


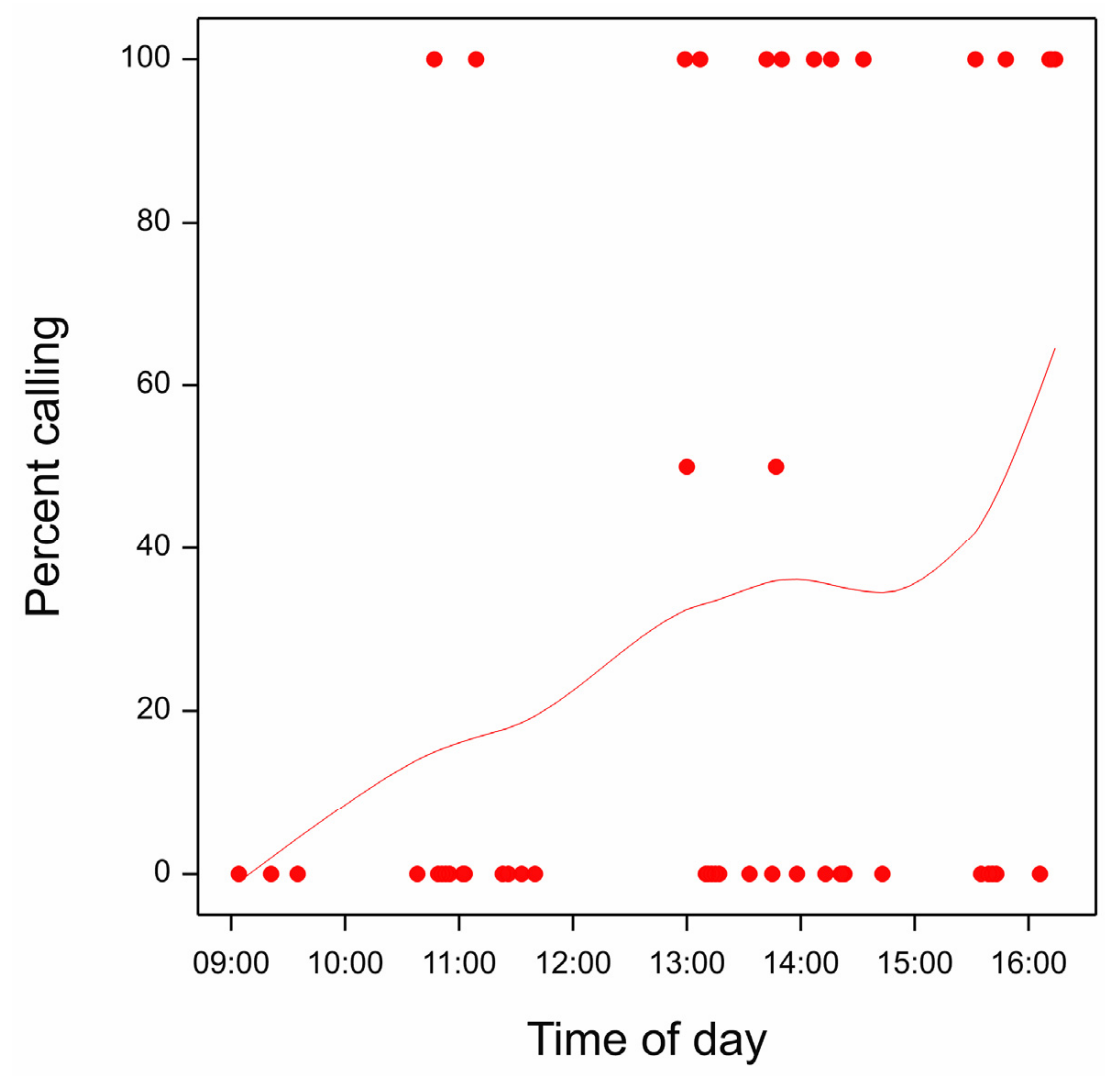

Figure 5. Percentage of recordings where Scolypopa australis emitted a calling signal, plotted against recording start time. The trend is highlighted with a cubic smoothing spline (red line).

\section{Discussion}

We observed that both virgin males and females of $S$. australis spontaneously emitted vibrational signals when placed on a plant (G. littoralis), as reported for other auchenorrhynchan species [18-21]. A male calling signal (MC) was recorded, where the amplitude and frequency progressively increased towards the end of the signal. A male calling signal increasing in amplitude through time was also observed in the leafhopper S. titanus $[8,17]$. Similar to this and other auchenorrhynchan species, S. australis males emitted a calling signal sooner than females after the final moult to the adult life stage [17-19]. In addition, the female calling signal (FC2) of $S$. australis resembled the female signal emitted by the spittlebug Philaneus spumarius (Linnaeus 1758) to express their willingness to find a mate [16,19]. It is therefore possible that either the FC1 or FC2 of $S$. australis expresses female proceptivity, although more data are needed to unveil the role(s) of male and female signals.

Regarding the signal structure, there was a large variation in the duration of each S. australis male calling signal, which, on average, lasted one minute. Female signals were, in contrast, shorter, lasting on average $12 \mathrm{~s}$. Moreover, female pulses had a more constant amplitude than male pulses. Given that vibrational signalling is energetically demanding, especially if the signals emitted are long and complex [22], S. australis male signals are likely to be more energetically costly than those of the females. Therefore, the passionvine hopper female may use the MC to evaluate the male quality and therefore decide whether to engage in a vibrational duet with the calling male, as suggested for other auchenorrhynchans $[16,19,22,23]$. In this regard, although we recorded signal exchanges between males and females of $S$. australis, we could not observe a vibrational duet leading to mating, and we did not analyse the signal characteristics because we had relatively few replicates. However, our preliminary results, and comparisons with the existing literature dealing with other auchenorrhynchans $[16,19,22,23]$ suggest that the MC and FC2 are probably used in the initial part of the mating sequence. 
S. australis calling activity increased later in the day. It is possible this could have been due to an increase in temperature during the day, or a build-up of chemical cues on the leaf apparatus, as leaves were not cleaned between individuals; however, this was not measured, as it was not the aim of the study. Given that the S. australis calling activity increased as the day progressed, it is possible that we could not record a vibrational duet because the insects may have responded to mating signals later in the day and/or into the evening. In the citrus flatid planthopper, Metcalfa pruinosa (Say 1830), for example, mating is achieved by means of vibrations and occurs at night [24]. In this light, further trials should be performed into the evening and night to assess whether the $S$. australis males and females engage in a vibrational duet at this time of the day. Similar to M. pruinosa and other auchenorrhynchans, $S$. australis can reach high population densities $[16,18,20,24]$; it is therefore possible that the substrate-borne vibrations emitted during the day by S. australis underlie aggregation, whereas the signals used in the evening and/or night are used to find a mate.

Indeed, further research should be conducted to unveil the vibrational repertoire of S. australis males and females and to assign a behavioural role to each signal. Once the vibrational signals and mating sequence of this pest are characterised, pre-recorded signals could be used to induce behavioural responses in order to assess whether they could be used as a management tool.

Our outcomes suggest that $S$. australis emit vibrations to communicate, although more research is still needed to confirm this by, for example, recording responses of conspecific insects to spontaneously emitted calling signals. If responses to calling signals can be demonstrated, assessments can be undertaken to determine whether mass traps or mating disruption tools based on vibrations could be developed, or whether they could complement the existing population-monitoring tools. If $S$. australis mating relies on vibrational signals, a future control strategy could involve the transmission of specific vibrations along the kiwifruit structural wires to interfere with the male-female communication. However, as $S$. australis is a polyphagous insect and moves into the kiwifruit orchard from the surrounding host plants [25], a management strategy could also involve the application of repellent vibrational signals, which could reduce the settling of the pest in the orchard. Harnessing gains in power production and storage, multi-modal traps including communication signals like vibrations and odours could be developed to catch novel pest insects. Moreover, the devices used to transmit the vibrational stimuli for one species will be able to play back disruption or repellent cues for a variety of species. The ultimate outcome is to reduce the persistence of multiple pests that communicate with vibrations (e.g., stinkbugs) [5], and thereby contribute to biosecurity preparedness and/or response. In the future, listening devices [26] in orchards to detect pests by detecting their calling signals from the foliage, when coupled with a call library, could provide early warning systems of the new pest as it expands its range.

The use of substrate-borne vibrational signals to lure and kill, disrupt mate-finding, or repel pests has the potential to be a paradigm shift, transforming the way horticultural industries like kiwifruit tackle insect pests.

Author Contributions: N.J.S., S.A., and L.D.S. conceived and designed the research. N.J.S. and S.A. conducted the research. R.C.B. undertook the analyses. All authors contributed to writing and revising the manuscript. All authors have read and agreed to the published version of the manuscript.

Funding: This research received no external funding.

Institutional Review Board Statement: Ethical review and approval were waived for this study due to the country of research (New Zealand) not requiring ethics approval for work on insects.

Informed Consent Statement: Not applicable.

Data Availability Statement: The data presented in this study are available on request from the corresponding author. 
Acknowledgments: The authors thank Donna Gibson for graphical support, Tom Sullivan for technical support, Christina Rowe and Cathy McKenna for insect supply, and David Logan and Ximena Nelson for their constructive comments on an earlier draft. The authors also thank three anonymous reviewers for their insightful suggestions that improved this manuscript.

Conflicts of Interest: The authors declare no conflict of interest. The funders had no role in the design of the study; in the collection, analyses, or interpretation of data; in the writing of the manuscript, or in the decision to publish the results.

\section{References}

1. Wilson, V.; Barker, A. Evaluating the Impact of Sooty Mould in New Zealand: Retrospective Report by Scarlatti for Zespri. 2020; p. 17.

2. Tomkins, A.R.; Holland, P.T.; Thomson, C.; Wilson, D.J.; Malcolm, C.T. Residual life of spinosad on kiwifruit-Biological and chemical studies. N. Z. Plant Prot. 1999, 52, 94-98. [CrossRef]

3. Holland, P.T.; McGhie, T.K.; Malcom, C.P. Residual life of pesticides on kiwifruit. In Proceedings of the New Zealand Weed and Pest Control Conference, Christchurch, New Zealand, 14-16 August 1984; pp. 136-141.

4. Hill, P.S.M.; Lakes-Harlan, R.; Mazzoni, V.; Narins, P.M.; Virant-Doberlet, M.; Wessel, A. Biotremology: Studying Vibrational Behavior; Springer: New York, NY, USA, 2019.

5. Mazzoni, V.; Polajnar, J.; Baldini, M.; Rossi Stacconi, M.V.; Anfora, G.; Guidetti, R.; Maistrello, L. Use of substrate-borne vibrational signals to attract the Brown Marmorated Stink Bug, Halyomorpha halys. J. Pest Sci. 2017, 90, 1219-1229. [CrossRef]

6. Polajnar, J.; Maistrello, L.; Ibrahim, A.; Mazzoni, V. Can vibrational playback improve control of an invasive stink bug? In Biotremology: Studying Vibrational Behavior; Hill, P.S.M., Lakes-Harlan, R., Mazzoni, V., Narins, P.M., Virant-Doberlet, M., Wessel, A., Eds.; Springer: New York, NY, USA, 2019; pp. 375-398.

7. Polajnar, J.; Eriksson, A.; Virant-Doberlet, M.; Mazzoni, V. Mating disruption of a grapevine pest using mechanical vibrations: From laboratory to the field. J. Pest Sci. 2016, 89, 909-921. [CrossRef]

8. Mazzoni, V.; Lucchi, A.; Čokl, A.; Prešern, J.; Virant-Doberlet, M. Disruption of the reproductive behaviour of Scaphoideus titanus by playback of vibrational signals. Entomol. Exp. Appl. 2009, 133, 174-185. [CrossRef]

9. Mankin, R.W. Vibrational trapping and interference with mating of Diaphorina citri. In Biotremology: Studying Vibrational Behavior; Hill, P.S.M., Lakes-Harlan, R., Mazzoni, V., Narins, P.M., Virant-Doberlet, M., Wessel, A., Eds.; Springer: New York, NY, USA, 2019; pp. 399-413.

10. Mazzoni, V.; Nieri, R.; Eriksson, A.; Virant-Doberlet, M.; Polajnar, J.; Anfora, G.; Lucchi, A. Mating disruption by vibrational signals: State of the field and perspectives. In Biotremology: Studying Vibrational Behavior; Hill, P.S.M., Lakes-Harlan, R., Mazzoni, V., Narins, P.M., Virant-Doberlet, M., Wessel, A., Eds.; Springer: New York, NY, USA, 2019; pp. 331-354.

11. Korinšek, G.; Tuma, T.; Virant-Doberlet, M. Automated vibrational signal recognition and playback. In Biotremology: Studying Vibrational Behavior; Hill, P.S.M., Lakes-Harlan, R., Mazzoni, V., Narins, P.M., Virant-Doberlet, M., Wessel, A., Eds.; Springer: New York, NY, USA, 2019; pp. 149-173.

12. Zespri. Available online: https://www.zespri.com/en-NZ/Sustainability-Our-Environment (accessed on 6 December 2021).

13. A European Green Deal. Available online: https://bit.ly/38rj2sM (accessed on 6 December 2021).

14. Broughton, W.B. Method in bioacoustic terminology. In Acoustic Behaviour of Animals; Busnel, R.G., Ed.; Elsevier: Amsterdam, The Netherlands, 1963; p. 324.

15. Alexander, R.D. Acoustical communication in arthropods. Annu. Rev. Entomol. 1967, 12, 495-526. [CrossRef]

16. Avosani, S.; Franceschi, P.; Ciolli, M.; Verrastro, V.; Mazzoni, V. Vibrational playbacks and microscopy to study the signalling behaviour and female physiology of Philaenus spumarius. J. Appl. Entomol. 2021, 145, 518-529. [CrossRef]

17. Mazzoni, V.; Prešern, J.; Lucchi, A.; Virant-Doberlet, M. Reproductive strategy of the Nearctic leafhopper Scaphoideus titanus Ball (Hemiptera: Cicadellidae). Bull. Entomol. Res. 2009, 99, 401-413. [CrossRef] [PubMed]

18. Nieri, R.; Mazzoni, V.; Gordon, S.D.; Krugner, R. Mating behavior and vibrational mimicry in the glassy-winged sharpshooter, Homalodisca vitripennis. J. Pest Sci. 2017, 90, 887-899. [CrossRef]

19. Avosani, S.; Daher, E.; Franceschi, P.; Ciolli, M.; Verrastro, V.; Mazzoni, V. Vibrational communication and mating behavior of the meadow spittlebug Philaenus spumarius. Entomol. Gen. 2020, 40, 307-321. [CrossRef]

20. Mazzoni, V.; Lucchi, A.; Ioriatti, C.; Virant-Doberlet, M.; Anfora, G. Mating behavior of Hyalesthes obsoletus (Hemiptera: Cixiidae). Ann. Entomol. Soc. Am. 2010, 103, 813-822. [CrossRef]

21. Derlink, M.; Abt, I.; Mabon, R.; Julian, C.; Virant-Doberlet, M.; Jacquot, E. Mating behavior of Psammotettix alienus (Hemiptera: Cicadellidae). Insect Sci. 2018, 25, 148-160. [CrossRef] [PubMed]

22. Kuhelj, A.; De Groot, M.; Pajk, F.; Simčič, T.; Virant-Doberlet, M. Energetic cost of vibrational signalling in a leafhopper. Behav. Ecol. Sociobiol. 2015, 69, 815-828. [CrossRef]

23. Eberhard, W.G. Copulatory courtship and cryptic female choice in insects. Biol. Rev. 1991, 66, 1-31. [CrossRef]

24. Virant-Doberlet, M.; Žežlina, I. Vibrational communication of Metcalfa pruinosa (Hemiptera: Fulgoroidea: Flatidae). Ann. Entomol. Soc. Am. 2007, 100, 73-82. [CrossRef] 
25. Gerard, P.J. Aspects of the Ecology of Scolypopa australis (Walker) (Homoptera:Ricaniidae) and Its Parasite Centrodora scolypopae (Valentine) (Hymenoptera: Aphelinidae). Ph.D. Thesis, The University of Waikato, Hamilton, New Zealand, 1985.

26. Mankin, R.; Hagstrum, D.; Guo, M.; Eliopoulos, P.; Njoroge, A. Automated applications of acoustics for stored product insect detection, monitoring, and management. Insects 2021, 12, 259. [CrossRef] [PubMed] 